\title{
Roles of long non-coding RNAs in colorectal cancer tumorigenesis: A Review
}

\author{
HALIMA SIDDIQUI $^{1}$, AYAT AL-GHAFARI ${ }^{1-3}$, HANI CHOUDHRY $^{1,3,4}$ and HUDA AL DOGHAITHER ${ }^{1}$ \\ ${ }^{1}$ Department of Biochemistry, Faculty of Science; ${ }^{2}$ Experimental Biochemistry Unit, King Fahd Medical Research Center; \\ ${ }^{3}$ Cancer and Mutagenesis Unit, King Fahd Medical Research Center; ${ }^{4}$ Cancer Metabolism and Epigenetic Unit, \\ Faculty of Science, King Abdulaziz University, Jeddah 23817, Kingdom of Saudi Arabia
}

Received November 22, 2018; Accepted May 16, 2019

DOI: $10.3892 /$ mco.2019.1872

\begin{abstract}
Long non-coding RNAs (lncRNAs) are newly identified potential biological and gene regulators. Similar to other cell-free circulating cancer-related nucleic acids, lncRNAs are released in the peripheral circulation of cancer patients and allow for non-invasive gene expression assessment. lncRNAs are considered to be promising biomarkers for cancer prognosis and diagnosis. Several lncRNAs have been found to regulate developmental processes in a number of biological disorders. Recent studies indicated that lncRNAs are associated with numerous diseases, most notably cancer, as they were found to be highly expressed or silenced in a number of human cancers, including colorectal cancer (CRC). Despite advances in the current detection methods, over half of cancer patients succumb to the disease, as several CRC cases are diagnosed at an advanced stage. Due to the lack of non-invasive and low-cost prognostic and diagnostic tests for CRC, the identification of novel, potentially effective biomarkers has been attracting increasing attention in recent cancer research. The present review focused on the most widely applied lncRNAs in cancer detection, including $\mathrm{CRC}$, in vitro.
\end{abstract}

\section{Contents}

1. Introduction

2. IncRNAs

3. Role of IncRNAs in CRC

4. Clinical applications of lncRNAs in CRC

5. Conclusions

Correspondence to: Dr Ayat Al-Ghafari, Department of Biochemistry, Faculty of Science, King Abdulaziz University, Building 7, Girls' Campus, Abdullah Al Sulaiman Street, Jeddah 23817, Kingdom of Saudi Arabia

E-mail: abalghafari@kau.edu.sa

Key words: colorectal cancer, long non-coding RNAs, prognosis, diagnosis, biomarkers

\section{Introduction}

Colorectal cancer (CRC) is considered to be the third most common type of cancer and the fourth leading cause of cancer-related mortality worldwide (1). The incidence of CRC is higher in developed countries with a Western culture (2). A number of etiological factors may be associated with the development of CRC, including environmental, genetic and epigenetic factors (3). CRC usually develops slowly over a period of 10-20 years (1). CRC commonly begins with an adenomatous polyp arising from the glandular epithelial cells in the colon or rectum, initiated by mutations in the adenomatous polyposis coli gene, with more mutations in tumor suppressor genes and oncogenes (4). The mortality risk of CRC increases due to the metastasis to other organs of the body (5). Therefore, there is an urgent need to elucidate the molecular mechanisms underlying the development and progression of CRC in order to develop new markers and therapeutic strategies (6). It was recently suggested that epigenetic alterations in CRC occur more frequently compared with genetic alterations (7); therefore, an increasing number of studies are focused on unraveling the different epigenetic mechanisms of CRC in order to discover new diagnostic biomarkers and design new therapies (8). The present review summarizes the classes of long non-coding (lncRNAs) and the most extensively investigated lncRNAs that have been shown to play a key role in CRC tumorigenesis in vitro.

\section{IncRNAs}

Of the human genome, $<2 \%$ encodes for proteins (9), while $75 \%$ of the genome is transcribed into non-coding RNAs (ncRNAs) (10). NcRNAs are classified into two groups according to their length (11), namely short ncRNAs that are $<200$ nucleotides in length (12), and long non-coding RNAs (lncRNAs) that have a length of $>200$ nucleotides (3).

lncRNAs are categorized into five classes: Bidirectional, sense, antisense, intergenic and intronic (13). The molecular functions of lncRNAs may be summarized as follows: i) Decoys, such as MALAT1 and PANDAR, which have the ability to bind and inhibit targets from binding to chromatin; ii) guides, such as HOTAIR, Xist and COLDAIR, which may recruit chromatin modification enzymes to their 
targets; iii) signals, including COLDAIR, lincRNA-p21 and HOTAIR, which reflect integrated transcription activity; and iv) scaffolds, such as ANRIL and HOTAIR, which may act as central platforms to assemble proteins $(14,15)$. Furthermore, lncRNAs are involved in multiple biological functions, such as regulating transcription, cell metabolism, RNA splicing and protein trafficking (16). IncRNAs are mostly transcribed by RNA polymerase II; apart from a few cases, they are derived from the antisense regions upstream of promoters (17). Recent research studies have demonstrated the importance of lncRNAs in a number of diseases, mainly cancer $(18,19)$, and different lncRNAs have been investigated in CRC (20). The identification of these IncRNAs as new molecular markers may be used in novel strategies for the prognosis, diagnosis and treatment of CRC $(3,20)$.

\section{Role of IncRNAs in CRC}

The functions of lncRNAs in CRC include RNA splicing, degradation, transcription and translation (21). They are involved in colorectal carcinogenesis by acting as oncogenes or tumor suppressor genes, as well as by interacting with DNA, RNA and proteins (22). The data obtained from several research studies have confirmed that lncRNAs participate in a competitive endogenous RNA network of tumor regulation by acting as endogenous miRNAs (23). IncRNAs have the ability to control gene expression during differentiation and developmental processes (24). Moreover, they act as gene expression regulators at the transcriptional, post-transcriptional, and epigenetic levels (21). A recent report highlighted the involvement of lncRNAs in CRC chemoresistance through several mechanisms, such as epigenetic modification, interaction with other miRNAs, acting as structural RNAs in scaffolding ribonuclear protein complexes, and regulating the expression of several genes that are involved in key cellular processes, including invasion and metastasis, apoptosis, cell proliferation and differentiation (25). Additionally, lncRNAs may be classed as competing endogenous RNAs (ceRNAs) that inhibit the targets of miRNAs; therefore, they act as miRNA sponges that regulate the migration, invasion and proliferation of CRC cells (26).

lncRNAs may be found in peripheral blood components, including serum and plasma (21). Some of these lncRNAs are upregulated in tumors and they act as oncogenes, while others act as tumor suppressors (12). In CRC cells and tissues, some IncRNAs tend to be overexpressed, and they are associated with poor CRC patient prognosis and metastasis (27). In the era of modern bioinformatics methods and high technologies, such as microarray assays, several expressed lncRNAs were found to be associated with CRC (28). In the following sections, some of the lncRNAs most commonly expressed in $\mathrm{CRC}$ tissues will be discussed in detail to reveal their contribution to CRC tumorigenesis.

HOTAIR. HOX transcript antisense intergenic RNA (HOTAIR) is transcribed from the HOXC locus-encoding $\sim 2.2 \mathrm{~kb}$ lncRNA (29). It interacts with polycomb repressive complex 2 (PRC2) in trans (8), altering cell epigenetics and gene expression (21). HOTAIR was found to be overexpressed in cancer epithelial cells, leading to histone methylation and cancer invasion (30). Moreover, its expression is closely associated with several proteins, such as vimentin, matrix metalloproteinase and E-cadherin, which are involved in CRC invasion, metastasis, tumor stage and angiogenesis (3). The expression of HOTAIR has been linked with metastasis and poor clinical outcome, not only in CRC but also in various tumors, such as breast, pancreatic and human epithelial ovarian cancers, as well as in hepatocellular carcinoma (31). A study conducted by Svoboda et al (30) on CRC blood samples and tissues demonstrated that the overexpression of HOTAIR is correlated with a high mortality rate for patients, and it can be used as a prognostic marker for sporadic CRC.

MALAT1. Metastasis-associated lung adenocarcinoma transcript 1 (MALAT1) is a lncRNA that interacts with pre-mRNA to localize transcriptional active genes in chromatin, and with serine/arginine splicing factor to regulate alternative splicing (32). In CRC tissues and cells, according to Yang et al (33), MALAT1 promotes cancer cell proliferation, invasion, migration and lymph node metastasis by activating AKAP-9, a gene linked to the development and metastasis of several cancers, such as oral cancer, melanoma, breast, thyroid and lung cancer. According to Hu et al (34), MALAT1 enhances AKAP-9 expression by promoting the expression of SRPK1 and phosphorylating SRSF1 in CRC cells.

CCAT1. Colon cancer-associated transcript 1 (CCAT1) is a newly identified lncRNA (35), which was found to be upregulated in all-stages of colorectal adenomas and adenocarcinomas. It serves as a target for real-time in vivo imaging (27). In particular, CCAT1 in human CRC tissues plays an oncogenic role in MYC activation, the target of an oncogenic miR-155, and it promotes cell proliferation and invasion by binding directly to the promoter region (28). On the other hand, Ma et al (14) revealed that the overexpression of CCAT1 in gallbladder cancer tissues and the knockdown of CCAT1 are associated with the invasion and proliferation of gallbladder cancer cells by affecting miRNA-218-5p.

CCAT2. Colon cancer-associated transcript 2 (CCAT2) is located on chromosome 8q24.21 (17). CCAT2 directly interacts with transcription factor 7-like 2, and it causes upregulation in the expression of MYC, which regulates miR-17p and miR-20a. This leads to genomic instability and promotes cancer metastasis (36). Moreover, CCAT2 is considered a target for therapy related to lncRNAs, and it has the ability to modify the clinical outcome (37). Additionally, CCAT2 plays an important role in loop formation between the MYC promoter and genomic locus rs6983267, and it acts as an activator of the MYC oncogene (23).

UCA1. Human urothelial carcinoma-associated 1 (UCA1) is an oncofetal gene that is responsible for embryonic development, and it was first expressed in bladder cancer (38). However, recent studies reported that UCA1 is also expressed in CRC tissues, and it plays a role in promoting cell proliferation by increasing CRC tumorigenesis and inhibiting apoptosis (39). UCA1 has several functions in the biology of cancer cells; for example, it promotes cell transformation and proliferation, increases invasion and mortality, and induces drug resistance 
Table I. Oncogenic long non-coding RNAs (lncRNAs) and their functions.

\begin{tabular}{|c|c|c|}
\hline LncRNA & Location & Function (Refs.) \\
\hline $\begin{array}{l}\text { Promoter of CDKNIA antisense DNA } \\
\text { damage activated RNA (PANDAR) }\end{array}$ & $6 \mathrm{p} 21.2$ & $\begin{array}{l}\text { Interacts with NF-YA to limit the expression of pro-apoptotic genes. } \\
\text { During DNA damage, it is induced by p53 and its } \\
\text { knockdown increases DNA damage-induced apoptosis (5). }\end{array}$ \\
\hline $\begin{array}{l}\text { Metastasis-associated lung } \\
\text { adenocarcinoma } \\
\text { transcript } 1 \text { (MALAT1) }\end{array}$ & 11q13.1 & $\begin{array}{l}\text { Interacts with pre-mRNA to localized transcriptional active } \\
\text { genes in chromatin and interacts with serine/arginine } \\
\text { splicing factor to regulate alternative splicing (32). } \\
\text { In CRC tissues, MALAT1 causes proliferation, } \\
\text { invasion and migration through activating AKAP-9 (33). }\end{array}$ \\
\hline $\begin{array}{l}\text { Colon cancer-associated } \\
\text { transcript } 1 \text { (CCAT1) }\end{array}$ & $8 \mathrm{q} 24.21$ & $\begin{array}{l}\text { Is expressed in human CRC tissues and plays an oncogenic role } \\
\text { by activating MYC. It binds directly to the promoter region } \\
\text { and promotes cell proliferation and invasion (63). }\end{array}$ \\
\hline $\begin{array}{l}\text { Colon cancer-associated } \\
\text { transcript } 2 \text { (CCAT2) }\end{array}$ & $8 \mathrm{q} 24.21$ & $\begin{array}{l}\text { Interacts with transcription factor 7-like } 2 \text { and causes upregulation } \\
\text { of MYC expression, which regulates miR-17p and miR-20a } \\
\text { and leads to instability and cell growth in colon cancer (16). }\end{array}$ \\
\hline $\begin{array}{l}\text { Brest cancer anti-estrogen } \\
\text { resistance } 4 \text { (BCAR4) }\end{array}$ & $16 \mathrm{p} 13.13$ & $\begin{array}{l}\text { Involved in the progression of breast cancer through binding to Smad } \\
\text { Nuclear-Interacting Protein } 1 \text { (SNIP1) and serine/threonine-protein } \\
\text { phosphatase } 1 \text { regulatory subunit } 10 \text { (PPP1R10 or PNUTS) and } \\
\text { activating hedgehog/GLI2 transcription program (64). }\end{array}$ \\
\hline $\begin{array}{l}\text { Human urothelial carcinoma- } \\
\text { associated } 1 \text { (UCA1) }\end{array}$ & $19 \mathrm{p} 13.12$ & $\begin{array}{l}\text { Associated with the expression of PDGFB, Fas, ATM } \\
\text { and steroid-sensitive gene. In bladder cancer, } \\
\text { UCA1 regulates CREB cell cycle by activating } \\
\text { P13K-AKT-dependent signaling pathways (16). }\end{array}$ \\
\hline $\begin{array}{l}\text { Prostate cancer-associated } \\
\text { transcript } 6 \text { (PCAT6) }\end{array}$ & 1q32.1 & $\begin{array}{l}\text { Promotes proliferation of prostate cancer cells through } \\
\text { the expression of two genes, Myc and p53 (65). }\end{array}$ \\
\hline $\begin{array}{l}\text { Maternally expressed } \\
\text { gene } 3 \text { (MEG3) }\end{array}$ & $14 q 32.2$ & $\begin{array}{l}\text { Acts as a tumor suppressor gene through activation of p53 } \\
\text { and downregulation of MDM2. Its re-expression } \\
\text { inhibits proliferation and induces apoptosis (32). }\end{array}$ \\
\hline
\end{tabular}

CRC, colorectal carcinoma; PDGFB, platelet-derived growth factor subunit B; P13K, phosphoinositide 3 kinase; AKT, protein kinase B.

in cancer cells (40). UCA1 is upregulated in CRC tissues, and the silencing of UCA1 may help inhibit CRC growth. Moreover, higher expression of UCA1 may result in larger tumor size and greater tumor depth (38).

CASC11. Cancer susceptibility candidate 11 (CASC11) is located on chromosome 8q24. It is upregulated in CRC cells and tissues, and its expression in CRC patients was found to be correlated with tumor size (41). In addition, the inhibition of CASC11 in CRC suppresses the metastasis and proliferation of tumor cells via its interaction with heterogeneous ribonucleoprotein, which protects $\beta$-catenin from degradation and the activation of transcription (42).

CRNDE. Colorectal neoplasia differentially expressed (CRNDE) was found to be $90 \%$ differentially overexpressed in $\mathrm{CRC}$ tissues. It was proven that insulin/IGFs regulate CRNDE through metabolic changes to evoke the Warburg effect of cancer cells (35). According to a recent report, colorectal neoplasia differentially expressed transcript variant 1
(Homo sapiens) (CRNDE-h) was highly expressed in CRC tissues and its elevation was correlated with tumor size, distant metastasis, poor overall survival rate and lymph node metastasis (43). Furthermore, Ding et al (44) reported that CRNDE levels were elevated in CRC tissues, and this upregulation was positively correlated with tumor size and stage. Moreover, knockdown of CRNDE may lead to increased in vitro and in vivo apoptosis of CRC cells (44). Han et al (45) observed that knockdown of CRNDE and miR-181a-5p microRNA resulted in inhibited cell proliferation and reduced chemoresistance through inhibiting the $\mathrm{Wnt} / \beta$-catenin signaling pathway.

PCAT-1. Prostate cancer-associated ncRNA transcript 1 (PCAT-1) was originally found in prostate cancer, and it may also be associated with CRC metastasis (46). The upregulation of PCAT-1 in cancer cells was associated with an increase in in vitro cell proliferation by promoting PRC2 expression (12). PCAT-1 was found to be upregulated in non-small-cell lung cancer cells and tissues and its overexpression promoted invasion, cell proliferation and migration (47). Furthermore, 
according to a research PCAT-1 was upregulated in CRC tissues and its overexpression was correlated with distant metastasis (48). Interestingly, the survival of CRC patients was highly correlated with the expression of PCAT-1 in colon tissues, and patients with high PCAT-1 expression had a poorer survival rate compared with those with lower PCAT-1 expression (48). A recent study demonstrated that PCAT-1 expression in CRC cells is highly correlated with c-myc, and that downregulation of PCAT-1 in CRC cells inhibited cell proliferation and blocked cell cycle transition by suppressing the expression of cyclins and c-myc (49).

H19. The H19 lncRNA is located on chromosome 11p15.5 (50). H19 is only upregulated during the early stages of embryogenesis, and it is downregulated after birth (51). H19 was identified from the transcription of the H19/insulin-like factor 2 gene cluster, and it is expressed by a maternal rather than paternal allele (5). Certain cancer-related proteins are regulated by H19, such as calneuron 1, ubiquitin ligase E3 family, and retinoblastoma tumor suppressor (52). According to a number of studies, the dysregulation of $\mathrm{H} 19$ exerts a number of effects on different cancers, including CRC (50). In CRC tissues and normal mucosa, differentially methylated region of $\mathrm{H} 19$ and its upstream of exon 3 of IGF2 were hypomethylated (53). Chen et al (5) demonstrated that the upregulation of $\mathrm{H} 19$ in CRC tissues is implicated in poor differentiation and high TNM stage.

GAS5. Growth arrest-specific transcript 5 (GAS5) is a lncRNA that acts as a tumor suppressor. According to previous studies, GAS5 has the ability to bind to the glucocorticoid receptor and affects the regulation of metabolism and cell survival (54). GAS5 was found to be downregulated in several cancers, including $\mathrm{CRC}$, and its low levels were associated with a larger tumor size, advanced TNM stage and low histological grade (55).

\section{Clinical applications of IncRNAs in colorectal cancer}

Since lncRNAs can be detected in almost all body fluids and tissues, and are also strongly resistant to degradation by RNases, they may be more accurate and effective than proteins, protein-coding RNAs and DNA in the diagnosis of CRC (23). lncRNAs may be detected in the peripheral blood, and they have been suggested as new non-invasive biomarkers in the diagnosis of tumors (56). Table I lists oncogenic lncRNAs associated with the prognosis of different cancers, including CRC. According to recent studies, IncRNAs act as molecular markers to predict chemotherapy response, specifically anti-VEGF and anti-EGFR targeted therapies in CRC (18). Some lncRNAs have been proven to be effective biomarkers in $\mathrm{CRC}$, and may help in early cancer detection and prevention of colorectal adenomas developing into malignancies; they may also play a role in early treatment. It has been demonstrated that IncRNA CCAT1, which was found to be a potential biomarker for the diagnosis of CRC, is overexpressed in the tissues, blood and stool of cancer patients (23). In addition, Zhao et al (46) reported that CCAT1 may be used for the screening of CRC as a predictive biomarker due to its high expression in the plasma of CRC patients. Furthermore, CRC-associated IncRNA induces multidrug resistance in CRC patients (3). Some lncRNAs, such as CRNDE, act as early biomarkers for the diagnosis of CRC (35). Recently, Dong et al (57) demonstrated that the combination of the KRTAP5-4 and MAGEA3 mRNAs with the BCAR4 IncRNA in the serum may be an effective marker for detecting CRC. Interestingly, some reports suggested that the knockdown of certain IncRNAs that are upregulated in CRC, such as MALAT1 and HOTAIR, leads to prominent anticancer effects $(58,59)$. According to a research conducted on MALAT1 and CRC tissues by Zheng et al (60), MALAT1 was highly expressed in CRC tissues, and its higher levels may serve as a negative prognostic marker in stage II and III cancer patients. HOTAIR may be used as a biomarker for cancer patients requiring special intensive care (30). Furthermore, HOTAIR was found to be associated with cancer metastasis and prognosis; for example, it is overexpressed in CRC tissues, particularly stage IV, and its level is correlated with liver metastasis (61). Moreover, the downregulation of HOTAIR decreases the metastasis and tumorigenesis of CRC by inhibiting CRC $\mathrm{CD} 133^{+}$cancer stem cells; therefore, it may act as a potential anticancer molecule that targets the inhibition of CRC stem cells (8). The IncRNA HULC was found to be highly expressed in CRC tissues alone, and serves as a biomarker for CRC (23). According to Yang et al (62), the FOXD2-AS1 lncRNA is significantly upregulated in CRC tissues and cells, and its knockdown suppresses CRC cell migration, proliferation and invasion; therefore, it may be an effective lncRNA in CRC treatment.

\section{Conclusion}

$\mathrm{CRC}$ is one of the most common cancers worldwide. In terms of occurrence, its incidence is more common in male rather than female patients. Cell-free circulating cancer-related nucleic acids, such as DNA, RNA, miRNA and lncRNA, are released in the peripheral circulation of cancer patients and allow for non-invasive detection of gene expression. IncRNAs acting as tumor biomarkers are valuable in the diagnosis and treatment of several types of cancers, including CRC. The irregular expression of IncRNAs is correlated with CRC development and metastasis. Furthermore, the unique expression of lncRNAs may be used to develop effective biomarkers. Further information regarding the role of IncRNAs in CRC may lead to novel approaches to the treatment of this disease. However, only limited numbers of identified and characterized lncRNAs have been correlated with CRC. Therefore, there is an urgent need to investigate the role of other IncRNAs to better understand the underlying mechanisms and to identify effective lncRNAs that may facilitate the prognosis, diagnosis and treatment of CRC.

\section{Acknowledgements}

Not applicable.

\section{Funding}

No funding was received.

\section{Availability of data and materials}

Not applicable. 


\section{Authors' contributions}

HS and AA designed the present review, collected information and wrote the manuscript. $\mathrm{HC}$ and $\mathrm{HA}$ wrote and reviewed the manuscript. HA submitted the manuscript. All authors have read and approved the final version of the manuscript.

\section{Ethics approval and consent to participate}

Not applicable.

\section{Patient consent for publication}

Not applicable.

\section{Competing interests}

The authors declare that they have no competing interests.

\section{References}

1. American Cancer Society: Colorectal Cancer Facts \& Figures 2014-2016. American Cancer Society, Atlanta, pp1-32.

2. Kheirelseid EA, Miller N, Chang KH, Nugent M and Kerin MJ: Clinical applications of gene expression in colorectal cancer. J Gastrointest Oncol 4: 144-157, 2013.

3. Luo J, Qu J, Wu DK, Lu ZL, Sun YS and Qu Q: Long non-coding RNAs: A rising biotarget in colorectal cancer. Oncotarget 8 : 22187-22202, 2017.

4. El Zoghbi M and Cummings LC: New era of colorectal cancer screening. World J Gastrointest Endosc 8: 252-258, 2016.

5. Chen T, Yang P, Wang H and He ZY: Silence of long noncoding RNA PANDAR switches low-dose curcumin-induced senescence to apoptosis in colorectal cancer cells. OncoTargets Ther 10 483-491, 2017

6. Rinn JL and Chang HY: Genome regulation by long noncoding RNAs. Annu Rev Biochem 81: 145-166, 2012.

7. Okugawa Y, Grady WM and Goel A: Epigenetic alterations in colorectal cancer: Emerging biomarkers. Gastroenterology 149: 1204-1225.e12, 2015.

8. Dou J, Ni Y, He X, Wu D, Li M, Wu S, Zhang R, Guo M and Zhao F: Decreasing lncRNA HOTAIR expression inhibits human colorectal cancer stem cells. Am J Transl Res 8: 98-108, 2016.

9. Peng W and Fan H: Long non-coding RNA PANDAR correlates with poor prognosis and promotes tumorigenesis in hepatocellular carcinoma. Biomed Pharmacother 72: 113-118, 2015.

10. Xiong XD, Ren X, Cai MY, Yang JW, Liu X and Yang JM: Long non-coding RNAs: An emerging powerhouse in the battle between life and death of tumor cells. Drug Resist Updat 26: $28-42,2016$

11. Shi Y, Liu Y, Wang J, Jie D, Yun T, Li W, Yan L, Wang K and Feng J: Downregulated long noncoding RNA BANCR promotes the proliferation of colorectal cancer cells via downregualtion of p21 expression. PLoS One 10: e0122679, 2015.

12. Smolle M, Uranitsch S, Gerger A, Pichler M and Haybaeck J: Current status of long non-coding RNAs in human cancer with specific focus on colorectal cancer. Int J Mol Sci 15: 13993-14013, 2014.

13. Xu Q, Deng F, Qin Y, Zhao Z, Wu Z, Xing Z, Ji A and Wang QJ: Long non-coding RNA regulation of epithelial-mesenchymal transition in cancer metastasis. Cell Death Dis 7: e2254, 2016.

14. Ma MZ, Chu BF, Zhang Y, Weng MZ, Qin YY, Gong W and Quan ZW: Long non-coding RNA CCAT1 promotes gallbladder cancer development via negative modulation of miRNA-218-5p Cell Death Dis 6: e1583,2015.

15. Bergmann JH and Spector DL: Long non-coding RNAs: Modulators of nuclear structure and function. Curr Opin Cell Biol 26: 10-18, 2014

16. Hao QQ, Chen GY, Zhang JH, Sheng JH and Gao Y: Diagnostic value of long noncoding RNAs for hepatocellular carcinoma: A PRISMA-compliant meta-analysis. Medicine (Baltimore) 96: e7496, 2017.
17. Wei MM and Zhou GB: Long non-coding RNAs and their roles in non-small-cell lung cancer. Genomics Proteomics Bioinformatics 14: 280-288, 2016.

18. Garajov I, Ferracin M, Porcellini E, Palloni A, Abbati F, Biasco G and Brandi G: Non-coding RNAs as predictive biomarkers to current treatment in metastatic colorectal cancer. In J Mol Sci 18 1547, 2017.

19. Fang Y and Fullwood MJ: Roles, functions, and mechanisms of long non-coding RNAs in cancer. Genomics Proteomics Bioinformatics 14: 42-54, 2016.

20. Ding J, Lu B, Wang J, Wang J, Shi Y, Lian Y, Zhu Y, Wang J, Fan Y, Wang Z, et al: Long non-coding RNA Loc554202 induces apoptosis in colorectal cancer cells via the caspase cleavage cascades. J Exp Clin Cancer Res 34: 100, 2015.

21. Xie X, Tang B, Xiao YF, Xie R, Li BS, Dong H, Zhou JY and Yang SM: Long non-coding RNAs in colorectal cancer. Oncotarget 7: 5226-5239, 2016.

22. Ragusa M, Barbagallo C, Statello L, Condorelli AG, Battaglia R, TamburelloL, Barbagallo D,Di Pietro C and Purrello M: Non-coding landscapes of colorectal cancer. World J Gastroenterol 21: 11709-11739, 2015.

23. Xu MD, Qi P and Du X: Long non-coding RNAs in colorectal cancer: Implications for pathogenesis and clinical application. Mod Pathol 27: 1310-1320, 2014

24. Cao J: The functional role of long non-coding RNAs and epigenetics. Biol Proced Online 16: 11, 2014.

25. Lizarbe MA, Calle-Espinosa J, Fernández-Lizarbe E, FernándezLizarbe S, Robles MÁ, Olmo N and Turnay J: Colorectal cancer: From the genetic model to posttranscriptional regulation by noncoding RNAs. BioMed Res Int 2017: 7354260, 2017.

26. Li H, Ma SQ, Huang J, Chen XP and Zhou HH: Roles of long noncoding RNAs in colorectal cancer metastasis. Oncotarget 8: 39859-39876, 2017.

27. Kam Y, Rubinstein A, Naik S, Djavsarov I, Halle D, Ariel I, Gure AO, Stojadinovic A, Pan H, Tsivin V, et al: Detection of a long non-coding RNA (CCAT1) in living cells and human adenocarcinoma of colon tissues using FIT-PNA molecular beacons. Cancer Lett 352: 90-96, 2014.

28. Wang J, Song YX, Ma B, Wang JJ, Sun JX, Chen XW, Zhao JH, Yang YC and Wang ZN: Regulatory roles of non-coding RNAs in colorectal cancer. Int J Mol Sci 16: 19886-19919, 2015.

29. Liu XH, Sun M, Nie FQ, Ge YB, Zhang EB, Yin DD, Kong R, $\mathrm{Xia} \mathrm{R}, \mathrm{Lu} \mathrm{KH}$, Li JH, et al: Lnc RNA HOTAIR functions as a competing endogenous RNA to regulate HER 2 expression by sponging miR-331-3p in gastric cancer. Mol Cancer 13: 92, 2014.

30. Svoboda M, Slyskova J, Schneiderova M, Makovicky P, Bielik L, Levy M, Lipska L, Hemmelova B, Kala Z, Protivankova M, et al: HOTAIR long non-coding RNA is a negative prognostic factor not only in primary tumors, but also in the blood of colorectal cancer patients. Carcinogenesis 35: 1510-1515, 2014

31. Deng J, Yang M, Jiang R, An N, Wang X and Liu B: Long non-coding RNA HOTAIR regulates the proliferation, self-renewal capacity, tumor formation and migration of the cancer stem- like cell (CSC) subpopulation enriched from breast cancer cells. PLoS One 12: e0170860, 2017.

32. Schmitt AM and Chang HY: Long noncoding RNAs in cancer pathways. Cancer Cell 29: 452-463, 2016.

33. Yang MH, Hu ZY, Xu C, Xie LY, Wang XY, Chen SY and Li ZG: MALAT1 promotes colorectal cancer cell proliferation/migration/invasion via PRKA kinase anchor protein 9. Biochim Biophys Acta 1852: 166-174, 2015.

34. Hu ZY, Wang XY, Guo WB, Xie LY, Huang YQ, Liu YP, Xiao LW, Li SN, Zhu HF, Li ZG, et al: Long non-coding RNA MALAT1 increases AKAP-9 expression by promoting SRPK1-catalyzed SRSF1 phosphorylation in colorectal cancer cells. Oncotarget 7: 11733-11743, 2016.

35. Ye LC, Zhu X, Qiu JJ, Xu J and Wei Y: Involvement of long non-coding RNA in colorectal cancer: From benchtop to bedside (Review). Oncol Lett 9: 1039-1045, 2015.

36. Wu L, Jin L, Zhang W and Zhang L: Roles of long non-coding RNA CCAT2 in cervical cancer cell growth and apoptosis. Med Sci Monit 22: 875-879, 2016.

37. Cătană CS, Pichler M, Giannelli G, Mader RM and BerindanNeagoe I: Non-coding RNAs, the Trojan horse in two-way communication between tumor and stroma in colorectal and hepatocellular carcinoma. Oncotarget 8: 29519-29534, 2017.

38. Han Y, Yang YN, Yuan HH, Zhang TT, Sui H, Wei XL, Liu L, Huang P, Zhang WJ and Bai YX: UCA1, a long non-coding RNA up-regulated in colorectal cancer influences cell proliferation, apoptosis and cell cycle distribution. Pathology 46: 396-401, 2014. 
39. Bian Z, Jin L, Zhang J, Yin Y, Quan C, Hu Y, Feng Y, Liu H, Fei B, Mao Y, et al: LncRNA-UCA1 enhances cell proliferation and 5-fluorouracil resistance in colorectal cancer by inhibiting miR-204-5p. Sci Rep 6: 23892, 2016.

40. Wang F, Li X, Xie X, Zhao L and Chen W: UCA1, a non-protein-coding RNA up-regulated in bladder carcinoma and embryo, influencing cell growth and promoting invasion. FEBS Lett 582: 1919-1927, 2008.

41. Zhang A, Zhao JC, Kim J, Fong KW, Yang YA, Chakravarti D, Mo YY and Yu J: LncRNA HOTAIR enhances the androgen-receptor- mediated transcriptional program and drives castration-resistant prostate cancer article LncRNA HOTAIR enhances the androgen- receptor-mediated transcriptional program and drives castration-resistant prostate. Cell Rep 13: 209-221, 2015

42. Shen P, Pichler M, Chen M, Calin GA and Ling H: To wnt or lose : The missing non-coding linc in colorectal cancer. Int J Mol Sci 18: 2003, 2017.

43. Liu T, Zhang X, Yang YM, Du LT and Wang CX: Increased expression of the long noncoding RNA CRNDE-h indicates a poor prognosis in colorectal cancer, and is positively correlated with IRX5 mRNA expression. Onco Targets Ther 9: 1437-1448, 2016.

44. Ding J, Li J, Wang H, Tian Y, Xie M, He X, Ji H, Ma Z, Hui B, Wang $\mathrm{K}$ and Ji G: Long noncoding RNA CRNDE promotes colorectal cancer cell proliferation via epigenetically silencing DUSP5/CDKN1A expression. Cell Death Dis 8: e2997, 2017.

45. Han P, Li JW, Zhang BM, Lv JC, Li YM, Gu XY, Yu ZW, Jia YH, Bai XF, Li L, et al: The lncRNA CRNDE promotes colorectal cancer cell proliferation and chemoresistance via miR-181a-5p-mediated regulation of $\mathrm{Wnt} / \beta$-catenin signaling. Mol Cancer 16: 9, 2017.

46. Zhao B, Lu M, Wang D, Li H and He X: Genome-wide identification of long noncoding RNAs in human intervertebral disc degeneration by RNA sequencing. BioMed Res Int 2016: $3684875,2016$.

47. Zhao B, Hou X and Zhan H: Long non-coding RNA PCAT-1 over-expression promotes proliferation and metastasis in non-small cell lung cancer cells. Int J Clin Exp Med 8: 18482-18487, 2015.

48. Ge X, Chen Y, Liao X, Liu D, Li F, Ruan H and Jia W: Overexpression of long noncoding RNA PCAT-1 is a novel biomarker of poor prognosis in patients with colorectal cancer. Med Oncol 30: 588, 2013.

49. Qiao L, Liu X, Tang Y, Zhao Z, Zhang J and Feng Y: Down regulation of the long non-coding RNA PCAT-1 induced growth arrest and apoptosis of colorectal cancer cells. Life Sci 188: 37-44, 2017.

50. Wang Y, Xue S, Liu X, Liu H, Hu T, Qiu X, Zhang J and Lei M: Analyses of Long Non-Coding RNA and mRNA profiling using RNA sequencing during the pre-implantation phases in pig endometrium. Sci Rep 6: 20238, 2016.

51. Ariel I, Miao HQ, Ji XR, Schneider T, Roll D, de Groot N, HochbergA and Ayesh S: Imprinted H19 oncofetal RNA is a candidate tumour marker for hepatocellular carcinoma. Mol Pathol 51: 21-25, 1998.
52. Schwarzenbach H: Biological and clinical relevance of H19 in colorectal cancer patients. EBioMedicine 13: 9-10, 2016.

53. Cui H, Onyango P, Brandenburg S, Wu Y, Hsieh CL and Feinberg AP: Loss of imprinting in colorectal cancer linked to hypomethylation of H19 and IGF2. Cancer Res 62: 6442-6446, 2002.

54. Kino T, Hurt DE, Ichijo T, Nader N and Chrousos GP: Noncoding RNA gas5 is a growth arrest- and starvation-associated repressor of the glucocorticoid receptor. Sci Signal 3: ra8, 2010.

55. Saus E, Brunet-Vega A, Iraola-Guzmán S, Pegueroles C, Gabaldón T and Pericay C: Long non-coding RNAs as potential novel prognostic biomarkers in colorectal cancer. Front Genet 7: 54, 2016.

56. Kishikawa T, Otsuka M, Ohno M, Yoshikawa T, Takata A and Koike K: Circulating RNAs as new biomarkers for detecting pancreatic cancer. World J Gastroenterol 21: 8527-8540, 2015.

57. Dong L, Lin W, Qi P, Xu MD, Wu X, Ni S, Huang D, Weng WW, Tan C, Sheng W, et al: Circulating long RNAs in serum extracellular vesicles: Their characterization and potential application as biomarkers for diagnosis of colorectal cancer. Cancer Epidemiol Biomarkers Prev 25: 1158-1166, 2016.

58. Gutschner T, Hämmerle M, Eissmann M, Hsu J, Kim Y, Hung G, Revenko A, Arun G, Stentrup M, Gross M, et al: The noncoding RNA MALAT1 is a critical regulator of the metastasis phenotype of lung cancer cells. Cancer Res 73: 1180-1189, 2013.

59. Gupta RA, Shah N, Wang KC, Kim J, Horlings HM, Wong DJ, Tsai MC, Hung T, Argani P, Rinn JL, et al: Long non-coding RNA HOTAIR reprograms chromatin state to promote cancer metastasis. Nature 464: 1071-1076, 2010.

60. Zheng HT, Shi DB, Wang YW, Li XX, Xu Y, Tripathi P, Gu WL, Cai GX and Cai SJ: High expression of lncRNA MALAT1 suggests a biomarker of poor prognosis in colorectal cancer. Int J Clin Exp Pathol 7: 3174-3181, 2014.

61. Kogo R, Shimamura T, Mimori K, Kawahara K, Imoto S, Sudo T, Tanaka F, Shibata K, Suzuki A, Komune S, et al: Long noncoding RNA HOTAIR regulates polycomb-dependent chromatin modification and is associated with poor prognosis in colorectal cancers. Cancer Res 71: 6320-6326, 2011.

62. Yang Y, Zhao L, Lei L, Lau WB, Lau B, Yang Q, Le X, Yang H, Wang C, Luo Z, et al: LncRNAs: The bridge linking RNA and colorectal cancer. Oncotarget 8: 12517-12532, 2017.

63. Cao Y, Shi H, Ren F, Jia Y and Zhang R: Long non-coding RNA CCAT1 promotes metastasis and poor prognosis in epithelial ovarian cancer. Exp Cell Res 359: 185-194, 2017.

64. Xing Z, Lin A, Li C, Liang K, Wang S, Liu Y, Park PK, Qin L, Wei Y, Hawke DH, et al: 1ncRNA directs cooperative epigenetic regulation downstream of chemokine signals. Cell 159: $1110-1125,2014$

65. Wan L, Zhang L, Fan K, Cheng ZX, Sun QC and Wang JJ: Knockdown of long noncoding RNA PCAT6 inhibits proliferation and invasion in lung cancer cells. Oncol Res 24: 161-170, 2016. 